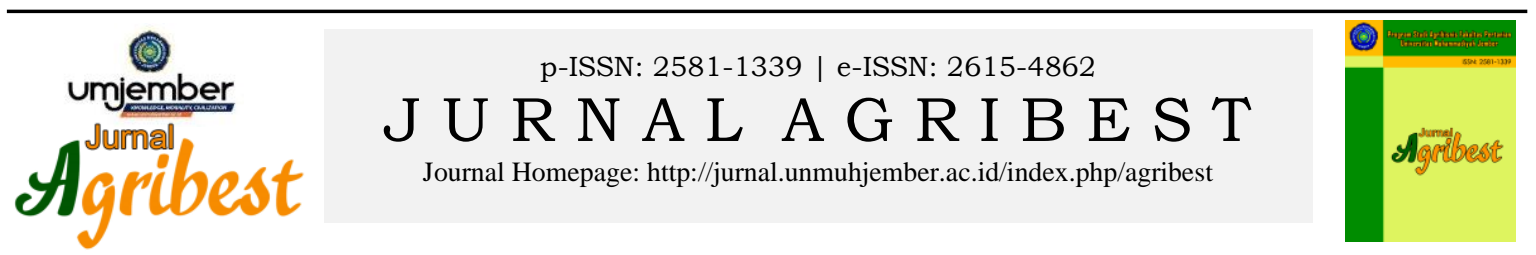

\title{
Minat Pekerjaan Pelajar Sekolah Menengah Atas Dan Mahasiswa Di Desa Pagelaran Kecamatan Ciomas
}

\author{
Job Interests of High School Students and Students in the Village of \\ Pagelaran, Ciomas District \\ Ridwan Ahmad Fauzan, Jabal Tarik Ibrahim, Livia Windiana \\ Universitas Muhammadiyah Malang \\ email: nvauzan10@gmail.com,jabal@umm.ac.id,windianalivia@yahoo.co.id
}

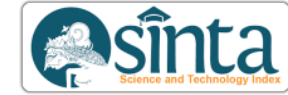

Received: 2020-10-15 Accepted: 2021-01-14 Published: 2021-03-25

This work is licensed under a Creative Commons Attribution 4.0 Copyright (c) 2021 Jurnal Agribest

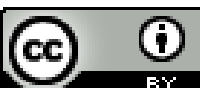

Corresponding Author: Ridwan Ahmad Fauzan, Universitas Muhammadiyah Malang, nvauzan10@gmail.com

\begin{abstract}
ABSTRAK
Menurunnya tingkat minat pemuda terhadap pekerjaan di bidang pertanian menjadi ancaman yang tidak bisa dihindari. Fakta menyatakan jumlah petani terus mengalami penurunan selama sepuluh tahun terakhir, presentasenya rata-rata penurunan mencapai 1 persen. Lokasi penelitian berada di Desa Pagelaran Kecamatan Ciomas Kabuaten Bogor. Tujuan penelitian ini adalah Menganalisis seberapa besar minat pemuda Desa Pagelaran terhadap pekerjaan di bidang pertanian, mengetahui faktor-faktor apa saja yang berkorelasi dengan pilihan pekerjaan pemuda di bidang pertanian, dan mengetahui jumlah dan presentase pilihan pekerjaan yang paling diminati oleh pemuda di Desa Pagelaran. Metode penelitian ini menggunakan data primer dan sekunder dengan analisis data deskriptif kuantitatif, metode pengambilan sambel menggunakan Propotionate Startified Random Sampling. Pengolahan data menggunakan uji Chi-square. Hasil dari penelitian ini adalah (1) Minat pemuda Desa Pagelaran terhadap bekerja di bidang pertanian masih tergolong rendah (2) Terdapat hubungan yang signifikan pada variabel internal (jenis kelamin, pengalaman bekerja \& tingkat kosmopolitan) pada variabel eksternal (sosialisasi pekerjaan) terhadap minat pemuda Desa Pagelaran untuk bekerja di bidang pertanian. (3) Sebagian besar Pemuda Desa Pagelaran lebih memilih bekerja di luar sektor pertanian.
\end{abstract}

Kata kunci: Minat, Pemuda Desa, Non Pertanian

\section{ABSTRAK}

The decrease of the youth's interest in agricultural work is an avoidable threat. The fact illustrates that the total farmer is decreasing for the last ten years, with the decrease average percentage reaches of 1 percent. The total farmer decreases is caused by the less people interest to be a farmer. Location of research was in Village of Pagelaran, District of Ciomas, Bogor Regency. The aim of this research is to analyze how big is the interest of the youth Villagers of Pagelaran in agricultural work, to recognize what factors do correlate with the choice of the youth in agricultural work, and also to recognize the total and percentage of the most interested work choices by the youth Villagers of Pagelaran. This research applies primary and secondary data, supported with descriptive quantitative data analysis, while sample taking method uses Proportionate Stratified Random Sampling. Data processing applies the Chi-square test. The results of this research are (1) the still lower interest of the youth of Pagelaran Village to work at agricultural sector (2) There are significant relations between the internal (sex, work experience \& Cosmopolitan level) and external variables (work socialization) to the youth villagers of Pagelaran to work at agricultural sector. (3) Most Youth Villagers of Pagelaran prefer to work beyond the agricultural sector.

Keywords : Interest, Youth Villagers, Non Agricultural Sector. 


\section{PENDAHULUAN}

Indonesia merupakan negara dengan penduduk terpadat ke empat di dunia dengan jumlah 269,6 juta jiwa atau 3,49\% dari total populasi dunia setelah Tiongkok (1.42 miliar jiwa), India (1.37 miliar jiwa), dan US (328 juta jiwa). Pertumbuhan populasi di Asia tenggara dengan 2,6 persen dari dunia namun menjadi tempat menetap bagi 8,3 peren populasi dunia. Jumlah pemuda atau milenial di Indonesia menurut hasil survei sosial ekonomi nasional (SUSENAS) tahun 2019 sebanyak 64,19 juta jiwa atau sama dengan seperempat dari total penduduk Indonesia. Berdasarkan Undang-undang No. 40 tahun 2009, pemuda adalah warga negara Indonesia berumur 16 hingga 30 tahun yang memasuki periode penting pertumbuhan dan perkembangan (Siti, 2020)

Permasalahan pembangunan pertanian di Indonesia adalah masalah Sumber Daya Mansia (SDM), diantaranya : kemampuan petani, peternak dan berkebun dalam memanfaatkan teknologi maju. Minat generasi muda untuk terjun di bidang pertanian dan keterbatasan tenaga penyuluh, pengamat OPT, pengawas benih tanaman serta kesehatan hewan. Kecenderungan pemuda tani meninggalkan sektor pertanian dipengaruhi oleh laju urbanisasi dan migrasi (Arvianti, 2015).

Ada berbagai faktor yang menyebabkan pemuda memasuki angkatan kerja. Salah satunya karena sudah tidak bersekolah lagi, baik sukarela maupun terpaksa. Sukarela, misalnya apabila seseorang telah menamatkan jenjang pendidikan tertentu, sedangkan yang terpaksa, misalnya karena alasan ekonomi seseorang memilih putus sekolah sementara masih berkeinginan untuk melanjutkan sekolah, dengan kondisi tersebut terpaksa harus bekerja atau mencari pekerjaan.

Minat pada bidang pertanian perlu mendapatkan perhatian khusus karena minat pada bidang pertanian merupakan salah satu faktor penunjang keberhasilan dalam melakukan usahausaha di bidang pertanian.Pengertian di atas dapat disimpulkan bahwa minat adalah kecenderungan hati yang tinggi terhadap memilih sesuatu dan keinginan untuk melakukan, mengetahui, memperngaruhi, memperlajari suatu hal tanpa ada yang menyuruh.

\section{METODE PENELITIAN}

Penelitian ini dilakukan di Desa Pagelaran merupakan Kecamatan Ciomas Kabupaten Bogor, Jawa Barat. Penelitian ini menggunakan data primer yang diperoleh dari responden penelitian dan data sekunder yang diperoleh dari sumber kedua dimana peneliti tidak terlibat secara langsung dalam pengumpulan data mentah (Ibrahim J.T., 2020). Penelitian lapang dilaksanakan pada 01 April 2019 - 29 Juni 2020.. Penelitian ini dimulai dengan pengambilan data primer pada responden melalui google form dengan kriteria (1) Pemuda dengan rentang usia 18 - 30 tahun, (2) Responden lulusan SMA/SMK sederajat dan srata 1 (S1)/D3 sederajat, (3) Responden sedang mencari pekerjaan menggunakan metode Stratified Random Sampling.

Data diolah dengan Microsoft Excel untuk mengetahui pilihan pekerjaan apa yang dimnati pemuda dengan uji Chi-square yaitu untuk mengetahui faktor-faktor apa saja yang berkorelasi dengan minat pemuda bekerja di bidang pertanian.

$$
\chi^{2}=\sum_{i=1}^{n} \frac{\left(O_{i}-E_{i}\right)^{2}}{E_{i}}
$$

Keterangan :

$\chi^{\wedge}=$ Distribusi Chi-square

Ei $\quad=$ Nilai ekspektasi ke-i

Oi $\quad=$ Nilai observasi (pengalaman) ke-i

Hipotesis :

H0 : tidak terdapat korelasi yang signifikat antara kedua variabel

$\mathrm{H} 1$ : terdapat korelasi yang signifikan antara kedua variable

Pengambilan keputusan berdasarkan nilai signifikan :

H0 ditolak apabila nilai Asym. Sig. (2-sided) $<0,05$

H0 diterima apabila nilai Asym. Sig. (2-sided) $>0,05$ 


\section{Karakteristik Responden}

\section{HASIL DAN PEMBAHASAN}

Responden pemuda Desa Pagelaran dalam penelitian ini secara menyeluruh memiliki status perkawinan belum menikah. Sebaran responden adalah usia $18-25$ tahun. Terbagi menjadi 3 strata pendidikan pada tabel 1 :

Tabel 1. Jumlah Umur dan Tingkat Pendidikan

\begin{tabular}{lllll}
\hline No & Pendidikan & Usia & Jumlah & $\%$ \\
\hline 1. & SMA/SMK & $18-19$ & 44 & 48 \\
2. & D3 & $20-21$ & 17 & 17 \\
3. & S1 & $20-30$ & 36 & 35 \\
\hline
\end{tabular}

Sumber : Olahan Data, 2020

Responden dalam penelitian ini adalah pemuda yang telah mengikuti wajib belajar selama 9 tahun menempuh pendidikan formal dan merupakan pemuda Desa Pagelaran. Kebanyakan pemuda Desa Pagelaran melanjutkan pendidikan hingga jenjang perkuliahan.

\section{Minat Pemuda Terhadap Bidang Pertanian}

Minat Pemuda terhadap pertanian adalah bagaimana tanggapan pemuda mengenai usaha dalam budidaya tanaman pertanian di Desa Pagelaran.

\section{Tabel 2. Minat Budidaya Tanaman Pertanian}

No. Minat Budidaya Tanaman Pertanian

1. Saya sudah menekuni cara budidaya pertanian sejak kecil Rataan Skor

2. Usaha budidaya pertanian merupakan usaha yang mudah dijalankan $\quad 2.04$

3. Usaha budidaya pertanian merupakan usaha yang sesuai dengan 2,01 keadaan lingkungan di Desa Pagelaran

4. Saya menggemari budidaya pertanian saat ini 1,82

\section{Sumber : Data Olahan, 2020}

\section{Faktor Internal}

Faktor internal yaitu factor yang berasal dari dalam keadaan spesifik individu yang berkaitan langsung dengan dirinya seperti jenis kelamin, keterampilan, pengalaman bekerja dan tingkat cosmopolitan.

Berikut hasil penelitian pada tabel 3.

Tabel 3. Hasil Uji Chi-square Hubungan Faktor Internal Dengan Minat Pemuda Desa Bekerja di Bidang Pertanian

\begin{tabular}{|c|c|c|c|c|c|c|c|c|}
\hline \multirow{3}{*}{\multicolumn{2}{|c|}{ Faktor Internal }} & \multicolumn{5}{|c|}{ Minat Bekerja Di Bidang Pertanian } & \multirow{4}{*}{$\begin{array}{c}\begin{array}{c}\text { Jumlah } \\
\text { (orang) }\end{array} \\
50\end{array}$} & \multirow{4}{*}{$\frac{\%}{52}$} \\
\hline & & \multirow{2}{*}{ Sig. } & \multicolumn{2}{|c|}{ Negatif } & \multicolumn{2}{|c|}{ Positif } & & \\
\hline & & & $\mathrm{n}$ & $\%$ & $\mathrm{n}$ & $\%$ & & \\
\hline \multirow{2}{*}{ Jenis Kelamin } & Laki-laki & \multirow{2}{*}{0,001} & 27 & 40 & 23 & 77 & & \\
\hline & Perempuan & & 40 & 60 & 7 & 23 & 47 & 48 \\
\hline \multicolumn{3}{|c|}{ Jumlah } & 67 & 100 & 30 & 100 & 97 & 100 \\
\hline \multirow{2}{*}{ Keterampilan } & Tidak & \multirow{2}{*}{0,575} & 12 & 18 & 4 & 13 & 16 & 16 \\
\hline & Memiliki & & 55 & 82 & 26 & 87 & 81 & 84 \\
\hline \multicolumn{3}{|c|}{ Jumlah } & 67 & 100 & 30 & 100 & 97 & 100 \\
\hline \multirow{2}{*}{$\begin{array}{c}\text { Pengalaman } \\
\text { Bekerja }\end{array}$} & Tidak & \multirow{2}{*}{0,007} & 50 & 75 & 14 & 47 & 64 & 66 \\
\hline & Memiliki & & 17 & 25 & 16 & 53 & 33 & 34 \\
\hline \multicolumn{3}{|c|}{ Jumlah } & 67 & 100 & 30 & 100 & 97 & 100 \\
\hline \multirow{2}{*}{$\begin{array}{c}\text { Tingkat } \\
\text { Kosmopolitan }\end{array}$} & Rendah & \multirow{2}{*}{0,133} & 0 & 0 & 1 & 3 & 1 & 1 \\
\hline & Tinggi & & 67 & 100 & 29 & 97 & 96 & 99 \\
\hline & Jumlah & & 67 & 100 & 30 & 100 & 97 & 100 \\
\hline
\end{tabular}




\section{Jenis Kelamin}

Tabel 1 dapat dilihat bahwa jumlah dari 97 masing-masing jenis kelamin responden yaitu laki-laki ada 50 orang (52\%) dan perempuan ada 43 orang (48\%). Hasil dari penyebaran kuisioner peneliti kepada responden perempuan rata-rata daya minat terhadap pekerjaan di bidang pertanian rendah karena bagi mereka pekerjaan di bidang pertanian lebih cocok untuk laki-laki dan bagi lakilaki memiliki minat bekerja dibidang pertanian lebih tinggi. Nilai signifikan dengan $0,001<0,05$ menjelaskan terdapat korelasi antara jenis kelamin dengan minat pemuda Desa Pagelaran terhadap bekerja di bidang pertanian.

\section{Keterampilan}

Keterampilan membantu pemuda untuk menumbuhkan minat terhadap pekerjaan yang akan dipilih. Keterampilan dibagi menjadi dua yaitu memiliki keterampilan dan tidak memiliki keterampilan. Bedasarkan data yang didapatkan dari tabel 1 pemuda Desa Pagelaran sebanyak 81 orang atau $84 \%$ memiliki keterampilan. Keterampilan yang dimiliki responden sebagian besar mampu mengoperasikan komputer, alat musik dan kesenian. Responden memiliki keterampilan didapatkan dari lingkungan sekitar, kursus, orang tua dan autodidak. Keterampilan yang mereka dapatkan tersebut diharapkan dapat membantu mereka untuk mendapatkan pekerjaan yang lebih baik nantinya. Nilai signifikan dengan 0,575 >0,05 menjelaskan tidak terdapat korelasi antara keterampilan dengan minat pemuda Desa Pagelaran terhadap bekerja di bidang pertanian

\section{Pengalaman Bekerja}

Pengalaman bekerja memberikan informasi terhadap dunia pekerjaan yang dimiliki oleh responden dalam menentukan pekerjaan apa yang akan dipilih. Berdasarkan data yang didapatkan dari hasil kuisioner pemuda Desa Pagelaran sebanyak 64 orang (66\%) tidak memiliki pengalaman bekerja dan sisanya sebanyak 33 orang (34\%) telah memiliki pengalaman bekerja. Alasan utama bagi responden yang tidak memiliki pengalaman bekerja dikarenakan mereka masih menempuh pendidikan di tingkat SMA/SMK/MA. Responden yang memiliki pengalaman bekerja sebagian besar telah menempuh di tingkat pendidikan. Nilai signifikan dengan 0,007 $<0,05$ menjelaskan terdapat korelasi positif antara pengalaman bekerja dengan minat pemuda Desa Pagelaran terhadap bekerja di bidang pertanian.

\section{Tingkat Kosmopolitan}

Kosmopolitan adalah keterbukaan seseorang terhadap informasi dengan melakukan kunjungan ke kota atau desa lainnya untuk mendapatkan berbagai informasi. Meskipun nilai Sig. Uji Chi-square variabel ini lebih kecil dari dua variable factor eksternal sebelumnya, namun tingkat kesalahan yang dimiliki masih di bawah batas kesalahan yang ditolelir, dimana tingkat kesalahan adalah 20\% (Lestari, 2017). Nilai signifikan dengan 0,133<0,2 menjelaskan terdapat korelasi positif antara tingkat kosmopolitan dengan minat pemuda Desa Pagelaran terhadap bekerja di bidang pertanian.

\section{Faktor Eksternal}

Faktor eksternal adalah kondisi luar pada diri pemuda yang dapat mempengaruhi minat pemuda terhadap pekerjaan di bidang pertanian. Faktor eksternal pemuda meliputi status social dan sosialisasi pekerjaan 
Tabel 3. Hasil Uji Chi-square Hubungan Faktor Eksternal Dengan Minat Pemuda Desa Bekerja di Bidang Pertanian

\begin{tabular}{|c|c|c|c|c|c|c|c|c|}
\hline \multirow{3}{*}{\multicolumn{2}{|c|}{ Faktor Eksternal }} & \multicolumn{5}{|c|}{ Minat Bekerja Di Bidang Pertanian } & \multirow{4}{*}{$\begin{array}{c}\text { Jumlah } \\
\text { (orang) }\end{array}$} & \multirow{3}{*}{$\%$} \\
\hline & & \multirow{2}{*}{ Sig. } & \multicolumn{2}{|c|}{ Negatif } & \multicolumn{2}{|c|}{ Positif } & & \\
\hline & & & $\mathrm{n}$ & $\%$ & $\mathrm{n}$ & $\%$ & & \\
\hline \multirow{3}{*}{ Status Sosial } & kebawah & \multirow{3}{*}{0,104} & 6 & 9 & 5 & 17 & & 11.3402 \\
\hline & Menengah & & 42 & 63 & 22 & 73 & 64 & 66 \\
\hline & Keatas & & 19 & 28 & 3 & 10 & 22 & 23 \\
\hline \multicolumn{3}{|c|}{ Jumlah } & 67 & 100 & 30 & 100 & 97 & 100 \\
\hline \multirow{2}{*}{$\begin{array}{l}\text { Sosialisasi } \\
\text { Pekerjaan }\end{array}$} & Rendah & \multirow{2}{*}{0,000} & 66 & 99 & 12 & 40 & 78 & 80 \\
\hline & Tinggi & & 1 & 1 & $\overline{18}$ & 60 & 19 & 20 \\
\hline \multicolumn{3}{|c|}{ Jumlah } & 67 & 100 & 30 & 100 & 97 & 100 \\
\hline
\end{tabular}

Sumber : Data Olahan, 2020

\section{Status Soial}

Status social dalam penelitian ini juga menghitung dari jumlah pendapatan orang tua selama satu bulan. Nilai signifikan dengan 0,104>0,05 menjelaskan tidak terdapat korelasi antara status sosial dengan minat pemuda Desa Pagelaran terhadap bekerja di bidang pertanian. Pemuda Desa Pagelaran dengan minat negative dari status social sebanyak 67 orang dan 30 orang lainnya positif, diantara penyebabnya adalah pemuda berasumsi bahwasanya bekerja di bidang pertanian tidak begitu menguntungkan dibanding bekerja di luar bidang pertanian.

\section{Sosialisasi Pekerjaan}

Sosialisasi pekerjaan (pertanian) yaitu proses seorang memperoleh pengetahuan, nilai dan sikap dari generasi tua ke generasi muda. Sosialisasi pekerjaan bertujuan memperkenalkan pekerjaan oleh orang tua kepada anaknya sehingga menimbulkan minat pada seorang anak. Nilai signifikan dengan $0,00<0,05$ menjelaskan terdapat korelasi positif antara sosialisasi pekerjaan dengan minat pemuda Desa Pagelaran terhadap bekerja di bidang pertanian. . Orang tua yang memberikan sosialisasi bekerja di bidang pertanian kepada responden berdampak positif terhadap hasil minat pemuda bekerja di bidang pertanian yaitu dengan jumlah 18 orang atau $60 \%$ dari total keseluruhan pemuda yang telah diberikan sosialisasi pertanian oleh orang tuanya.

\section{Pilihan Pekerjaan}

Berdasarkan data yang didapatkan dari responden pemuda Desa Pagelaran untuk penelitian ini, berikut daftar pilihan pekerjaan pemuda Desa Pagelaran pada tabel 4.

Tabel 4. Jumlah dan Presentase Responden Berdasarkan Pilihan Pekerjaan

\begin{tabular}{llcc}
\hline No & \multicolumn{1}{c}{ Pilihan Pekerjaan } & Jumlah & $(\boldsymbol{\%})$ \\
\hline 1. & Apoteker & 2 & 2 \\
2. & Arsitek & 2 & 2 \\
3. & Budidaya & 1 & 1 \\
4. & Distributor & 2 & 2 \\
5. & Dokter & 3 & 3 \\
6 & Dosen & 3 & 3 \\
7. & Guru & 7 & 7 \\
8. & Karyawan/kantoran & 19 & 20 \\
9. & Pilot & 2 & 2 \\
10. & PNS & 29 & 30 \\
11. & Pramugari/a & 3 & 3 \\
12. & Selebgram & 3 & 3 \\
13. & Youtuber & 2 & 2 \\
14. & Tentara & 5 & 5 \\
15. & Wirausaha & 14 & 14 \\
\hline \multicolumn{2}{c}{ Total } & $\mathbf{9 7}$ & $\mathbf{1 0 0}$
\end{tabular}

Sumber : Data Olahan, 2020 
Secara garis besar pemuda Desa Pagelaran memilih pekerjaan diluar sektor pertanian atau non pertanian dengan jumlah 94 orang (96\%). Pemuda Desa Pagelaran ada 3 orang memilih pekerjaan di bidang pertanian dalam hal budidaya diantaranya budidaya ternak (ikan lele, hidroponik), distributor (telur, bawang merah) dan distributor beras. Hal ini disebabkan orang tua responden bekerja pada bidang tersebut dan memberikan sosialisasikannya kepada anaknya.

\section{KESIMPULAN}

Minat pemuda Desa Pagelaran terhadap bekerja di bidang pertanian masih tergolong rendah dengan karakteristik responden berpendidikan yang relatif tinggi dikarenakan pemuda Desa Pagelaran sadar akan pentingnya pendidikan untuk masa depan, latar belakang orang tua yang berpendidikan dan tidak adanya angka pernikahan pada responden penelitian ini.

Terdapat hubungan yang signifikan pada variabel internal (jenis kelamin, pengalaman bekerja \& tingkat kosmopolitan) pada variabel eksternal (sosialisasi pekerjaan) terhadap minat pemuda Desa Pagelaran untuk bekerja di bidang pertanian.

Pemuda Desa Pagelaran lebih memilih bekerja di luar sektor pertanian seperti PNS dan kantoran / karyawan swasta dengan harapan pendapatan yang mereka terima sesuai dengan standar upah minimum rata-rata (UMR) sekitar daerah tersebut.

\section{DAFTAR PUSTAKA}

Arvianti, E. Y. (2015). Minat Pemuda Tani Terhadap Transformasi Sektor Pertanian Di Kabupaten Ponorogo. Buana Sains Vol 15 No 2: 181-188, 2015 183, 15(2), 181-188.

BPS. (2017). Jumlah Rumah Tangga Petani Tahun 2012. Jakarta.

Departemen Tenaga Kerja Dan Transmigrasi, D. (2012). Penduduk Yang Bekerja Menurut Golongan Umur Dan Lapangan Usaha Retrieved From Pusdatinaker.Balitfo.Depnakertrans.Go.Id/?Section=Pyb\&Period=2012-0201\#Gotoperiod

Eva, R., \& Siagian, F. (2015). Pengaruh Minat Dan Kebiasaan Belajar Siswa. Jurnal Formatif 2(2): 122-131 Issn: 2088-351x, 2(20), 122-131.

Hendri, M., \& Wahyuni, E. S. (2013). Perception On Agriculture Jobs And Job Preference Among Youth Unemployed In Cihideung Udik , Ciampea District, Bogor Regency. Jurnal Penyuluhan, Maret 2013 Vol. 9 No. 1 Data, 9(1), 49-68.

Ibrahim, J. T., \& Mazwan, M. Z. (2020). Structural Transformation Of Agricultural Sector In East Java Indonesia. Ssrg International Journal Of Economics And Management Studies (SsrgIjems) - Volume 7 Issue 3 - March 2020, 7(3), 1-7.

Khotnitan, D., \& Utami, B. N. (N.D.). Pertanian Malang Dwi Khonitan Bekti Nur Utami. Jurnal Sains Psikologi, Jilid 8, Nomor 1, Maret 2019, Hlm 162-170 Revolusi, (2016), 162-170.

Lestari, J. W. (2017). Kelayakan Dan Adopsi Usahatani Konservasi Sayuran Dataran Tinggi. Brawijaya University.

Meitasari, I. (2017). Minat Pemuda Desa Untuk Urbanisasi Di Desa Sukasari, Kabupaten Majalengka, Jawa Barat*. Jurnal Geografi Edukasi Dan Lingkungan, Vol. 1, No. 1, Juli 2017: 36-47 37, 1(1), 36-47.

Na'imah, T., \& Raharjo, P. (2012). Pengembangan Modul Bimbingan Karir Untuk Meningkatkan Jiwa Wirausaha Remaja. Pengembangan Modul Bimbingan Karir Untuk Meningkatkan Jiwa Wirausaha Remaja Proyeksi, Vol. 7 (1) 2012, 55-66, 7(1), 55-66.

Pemuda, K. N. (2008). Penyajian Data Informasi Kementerian Negara Pemuda Dan Olahraga Tahun 2008 (T. Penyusun, Ed.). Jakarta: Kementerian Negara Pemuda Dan Olahraga. 
Setiawan, S. A. (2010). Fakultas Ekonomi Universitas Diponegoro Semarang 2010. Diponogoro University.

Singgih, S. (2014). Statistik Multivariat Edisi Revisi (2nd Ed.). Jakarta: Pt. Elex Media Komputindo.

Siti, M. (2020). Pemuda Milenial Menyongsong Era Bonus Demografi.

Sofya, C., B, C., \& R, L. (2018). Persepsi Generasi Muda Terhadap Kegiatan Pertanian Di Kelurahan Buha Kecamatan Mapanget Kota Manado. Agri-Sosioekonomi Unsrat, Issn 19074298, Volume 14 Nomor 3, September 2018 : 123 - 130 Persepsi, 14(September), 123-130.

Suliyanto. (2018). Metode Penelitian Bisnis (A. Cristian, Ed.). Yogyakarta: Penerbit Andi.

Suprayogi, O. G. I., Noor, T. I., \& Yusuf, M. N. (2018). Persepsi Dan Minat Mahasiswa Program Studi Agribisnis Universitas Galuh Ciamis Untuk Berkarir Di Bidang Pertanian. Jurnal Ilmiah Mahasiswa Agroinfo Galuh Volume 6, Nomor 3,September 2019: 517-531 Menggunakan, 507-531.

Susilowati, S. H. (2016). Serta Implikasinya Bagi Kebijakan Pembangunan Pertanian Farmers Aging Phenomenon And Reduction In Young Labor: Its Implication For Agricultural Development. 38 Forum Penelitian Agro Ekonomi, Vol. 34 No. 1, Juli 2016: 35-55, 35-55.

Suyanto, \& Sudarso. (2004). Sosiologi, Teks Pengantar Dan Terapan (S. B, Ed.). Jakarta: Kencana Prenada Media Group.

Tarik Ibrahim, J. (2020). Metode Penelitian Sosial Ekonomi Pertanian (Cetakan Pe; Riyantono, Ed.). Malang: Umm Press.

Yunita. (2011). Strategi Peningkatan Kapasitas Petani Padi Sawah Lebak Menuju Ketahanan Pangan Rumah Tangga Di Kabupaten Ogan Ilir Dan Ogan Komering Ilir Provinsi Sumatera Selatan. Ipb. 